\title{
The current state of research on networks in China's business system
}

\author{
Johannes Meuer and Barbara Krug \\ (jmeuer@rsm.nl / bkrug@rsm.nl) \\ Rotterdam School of Management, Erasmus University \\ PO Box 1738, 3000 DR Rotterdam, The Netherlands \\ Phone: +31 10408 -2813 / -2736 \\ Fax: +31 104089015
}

\begin{abstract}
The purpose of the paper is to assess the current state of network research in China's business system. Research on networks has developed significantly during the last decades in regards to analytic techniques, number of research projects, and accumulated findings. While research on networks in China has always received much attention - not least because networks are (still) considered one of the major forces behind the country's socio-economic change - this development has also had an effect on how research on generic networks in China is being conducted. How Chinese networks are modelled, which aspects remain controversial in the academic debate, and which conclusions the different studies offer asks for a systematic comparison. The paper, based on an extensive literature research, therefore relies on a framework of theoretical concepts underlying the study of networks which allows a categorization of the dominant (generic) forms of Chinese networks as discussed in major journals. The study on the one hand is descriptive by filtering the diverse literature of network research on China's business system. On the other hand, it serves to identify gaps and shortcomings of the current literature in this field pointing to future research directions. We identify four generic types of networks, Chinese business groups (qiyejituan), Overseas Chinese Communities, networks of social relations (guanxi), and Network Capitalism, as an alternative economic model. As the study shows, the research approaches to these networks are extremely diverse both in description and analysis. A focus on the identified gaps within each type of network and a convergence between the types of networks should yield to further insights into the study of networks as well as their implications for economic systems.
\end{abstract}

Keywords: Social Networks, Organizational Networks, China 


\section{Introduction}

“...if one would understand Asian economic development, one must first understand Asian business networks."

Gary G. Hamilton (Hamilton, 1996)

\subsection{Network research in China}

Research on social and organizational networks in China has increased significantly during the 1970s when Western social sciences started to focus on the concept of networks. Central to the study of networks in China has always been the attempt to explain the uniqueness if not Chineseness of social and organizational networks. Most of this research had initially been dominated by anthropologists and sinologists (Anonymous, 1991; van der Sprenkel, 1991; Whyte, 1991; Zheng, 1991), seemingly defying the usual social science concepts. Only recently did network studies in China include social science considerations, while simultaneously general network studies looked for ways how to better include the notion of culture (Boisot \& Child, 1988; Krug \& Hendrischke, 2007).

Today, network research in general as well as network research in China has reached a mature state (e.g. Academy of Management Journal, 1997; Acta Sociologica, 1994; Organization Studies, 2003; Strategic Management Journal, 2000). One indicator is the publication of special issues in academic journals. As calls for special issues are regularly expressed when a topic has attracted the attention of more than one academic field, to the effect that large numbers of theoretical and empirical contributions appeared in too dispersed location, such special issues point to the need to 'take stock'.

\subsection{Core question and purposes}

The purpose of this study is to offer an accurate description of the current state of research on generic social and organizational networks in China as published in academic journals. The focus will lie on networks claimed to be relevant for explaining the socioeconomic development of China, highlighting how the concept of network is being applied in the context of China. In the most general terms, networks here will therefore only be seen as "an interconnected group of people or organizations having certain 
connections which may be exploited to gain preferment, information, etc.” (OED, 2006). In a first step the development of research in this field will be described, before the focal findings and trends both in empirical and in theoretical research will be singled out. Such a procedure allows for identifying gaps and shortcoming in present research concepts and practices. Finally, based on these findings, directions for future research will be suggested.

\subsection{Structure of the paper}

The remainder of this paper is structured as follows. In the second section, the research approach will be outlined. Data sources, selection mechanisms, characteristics of the selected publication set, and the analytical tool developed for this study will be described. Those publications in the list of references marked with an asterisk are included in the selected set of literature on networks in China. The findings are reported in section three, introducing the results with a broader analytical description, which allows constructing four distinct types of networks that dominate the literature on networks in China. After a summary in section four, the final section will discuss the overall implications of this study.

\section{Research approach}

The literature review employed a number of electronic databases searching for 'networks' and 'China'. This set of papers forms the base for clustering the different articles according to selected criteria. For doing so a classification scheme was developed including categories from other studies which have attempted to systemize network research while additional criteria were added when this promised more insights. In the following, the three main elements for the selection and analysis of the literature will be explained in more detail.

\subsection{Data source}

Three sources for selecting relevant publications on networks in China were used. After an initial research on electronic databases, namely SSRN, JSTOR, and EBSCO, all studies published in academic journals that responded to the search criteria 'China' and 'network' were identified. The initial collection required to exclude 'irrelevant' studies to 
avoid a bias toward irrelevant data that arises when the findings of all studies are equally weighted. The number of studies in the data set was therefore reduced by eliminating publications on technical and logistical networks. Articles were ordered according to the impact factor of the journal they have been published in. ${ }^{1}$ Journals relevant for sociological studies on China were added. References of the selected number of publications were examined, adding frequently occurring publications that had not been detected before. In case of doubt, abstracts of the given papers were obtained in order to assess the relevance of the publication. Finally, the list was cross-checked by colleagues with professional experience in the field.

The remaining set allows to assess findings in the field over time and to identify more recent consensus about specific research topics and approaches. It includes a total of 62 publications that appeared between 1985 and 2006 with an increasing number in the years since 1995. The data set includes empirical as well as theoretical-conceptual contributions.

\subsection{Classification scheme}

In order to systematically analyse the selected literature, a classification scheme was developed that addressed categories on network research, methodology, and lines of arguments. Some of the categories were derived from Borgattis' and Fosters' (2003) classification on network research in general (Borgatti \& Foster, 2003). Two further categories aiming at discriminating the differing lines of arguments were provided by Krug (Krug, 2003). When required categories were adapted and extended according to recent developments in the field of network analysis. The remaining categories were added, mainly addressing methodological aspects of network research. The following subsections describe the classification scheme in detail and are structured as follows: first, categories for assessing streams of network research in the overall scientific field are explained (categories 1-4); second, methodological issues are discussed (categories 59) followed by third, categories that assess the opinions expressed by authors regarding the network at stake (categories 10-13). Each paragraph discusses a separate category

\footnotetext{
${ }^{1}$ The current ERIM's journal list 2006-2008 (EJL) served as a guideline, see http://www.erim.eur.nl
} 
with its dimensions; the label of each category is given in italic letters. The presentation of the results in section three will follow the same order.

\section{Categorizing general network research}

Borgatti et al. (2003) identify among others six areas of network research (Borgatti et al., 2003). 'Social Capital', closely related to the works of Burt and Coleman refers to the social value of ties, enhancing among others organizational aspects such as leadership, mobility, employment, individual and team performance (Burt, 1997; Coleman, 1990). 'Social Embeddedness' mainly builds upon Granovetters' notion and focuses on the embeddedness of economic exchanges in social networks thereby predominantly relating to performance benefits (Granovetter, 1985; Uzzi, 1997). Employing the Williamson notion of networks as hybrids between market and hierarchies led to the research area of ‘Organizational Networks’ or 'Network Organizations'. The area is conceptually divided. While accepting the focus on exchange among semi-autonomous organizations (Williamson, 1975) the question whether organizations need to convert into networks, i.e. organizational networks or whether organizations already constitute an assembly of networks, i.e. network organizations is not settled (Borgatti et al., 2003). Studies on 'Joint Ventures' and 'Inter-firm' alliances assess the impact of such forms of collaboration on firm-level outputs, more precisely organizational learning or innovation. The area of 'Social Cognition' is concerned with the way networks are perceived as an entity by individuals members (Borgatti et al., 2003; DiMaggio, 1997) arguing that cognition of networks affects interaction and interaction in turn changes the network. The last area of network research on 'Group Processes' concerns the interaction of “... proximity, similarity of beliefs and attitudes, amount of interaction, and effective ties.” (Borgatti et al., 2003: 998).

The second category regards the direction of causality. Causality offers insights into the understanding of research on networks and can either be directed to understanding the causes of networks, i.e. from where, how, and why network structures evolve, or to understanding the consequences of networks, i.e. what they contribute to overall outcome, what they offer their members, why they persist, or how they can be used as an (exogenous) variable for explaining other developments and trends (Borgatti et al., 2003; 
Hendrischke, 2004). Studying the dimension of 'causes' leads to the search for evolutionary patterns illustrating that networks can either emerge generically, intentionally, or based on cultural and traditional reasons.

The third category examines two explanatory goals in the analysis distinguishing between studies that try to prove homogeneity between networks or actors as opposed to studies that attempt to explain differences in performance of networks or actors.

The last category assessing the literature on networks concerns the explanatory mechanism asking how the link between network and explanatory goal is modelled (Borgatti et al., 2003). While some studies focus on the content of ties and relations between network members (connectionists), others emphasis structural aspects such as brokerage positions, centrality, or embeddedness (structuralist).

\section{Categorizing methodological aspects}

The following five categories refer to methodological aspects. The findings in this regard were not so much used to classify the studies but rather to address preferences in the research on networks in China.

The intentions of researchers can be followed in assessing first what they singled out as unit of analysis. Network studies usually settle for one of the four following alternatives: individual actors, dyadic relations, networks, or multiple-networks. The difficulty in defining an appropriate unit of analysis lies in confusions regarding theoretical and methodological similarities between macro, meso, and micro levels in a business environment, in which clear authority relations cannot (yet) be identified. An organization can be considered a single actor in a network or can be regarded as a network itself (Borgatti et al., 2003). Multiple network analysis would argue, that an organization consists of a number of networks, such as an advice network, an information network, or a friendship network (Klein, Lim, Saltz, \& Mayer, 2004) while concepts which focus on firms find it hard to delineate the boundaries of a firm (Holmström \& Roberts, 1998; Krug, 2006).

Another methodological category concerns the distinction between conceptualtheoretical and empirical studies. 
In the latter case, different methods of data collection (category 7) and data analysis (category 8), either qualitative or quantitative, can be distinguished.

Moreover, the findings of qualitative analysis, in particular interview techniques are taken seriously when it is argued that a number of scales require an adaptation to the specific cultural environment such as China. Because of variations in the perception of Lickert scales or the impact of social desirability biases for example, researchers not developing appropriate scales are in danger of using invalid measurements, besides spending time and resources on invaluable procedures (Abhik, Walters, \& Luk, 2001). Farh et al. (2006) distinguish between an etic, i.e. universal, and an emic, i.e. specific (to cultural context), approach to scale development which should be made explicit in fieldwork (Farh, Cannella, Lee, \& Lee, 2006; Farh, Tsui, Xin, \& Cheng, 1998).

\section{Categorizing opinions expressed by authors}

The last five categories look at opinions expressed in the studies regarding the networks at stake. Studies might for example suggest certain origins of networks as already described above. The origins can be either of an intentional, generic, or culturalhistorical nature.

How the type of governance mechanism of networks is evaluated forms another category. Studies distinguish between 'self-enforcing' governance mechanism prevalent in those cases where the social structure of the network itself serves to govern the behaviour of individual actors, and 'trusted-third party' mechanisms when referring to cases in which reputation mechanisms or referral to arbitration are focal governance mechanisms (Krug, 2003). While the cases above provide examples of private and market conforming forms of governance, other networks rely on legitimised 'authority-driven' mechanisms that are governed by fiat of a certain body, such as government agencies.

Studies question the functional value of networks which can either be assumed to exist in a reduction of costs or risk, an improvement in coordination, or access to resources (Krug, 2007).

Moreover, most studies offer an estimation about the future of networks under research. This question frequently occupies the academic community, which has not yet 
reached a consensus. It was differentiated between a diminishing, prevailing, or strengthening significance of networks as claimed by authors.

Finally studies can be distinguished according to their standpoint whether Western theories were applied to China as a case, or whether China is considered a research topic sui generis. Especially this last aspect indicates whether researchers believe China to offer unique insights into and the ability to challenge existing theories and concepts, or whether its growing significance merely follows existing patterns.

In what follows, all aspects as seen in the different studies will be evaluated to show whether there is a trend in research and where the academic community is converging to one opinion.

\section{Findings}

The sample shows that four generic types of networks are at the centre of the analysis. They are first, networks of organizations in business when referring to qiye jituan, i.e. state-promoted business groups; second, networks of organizations in the civic society when discussing the role of Overseas Chinese Communities; third, networks of social relationships when referring to guanxi, and fourth, the notion of 'network-' or 'clan-' capitalism as an alternative economic model.

This section is structured as follows. It starts with general information on the selected sample against which the more specific information on the four networks can be contrasted. The following subsections comprise specific information regarding the four identified generic networks.

\subsection{Descriptive analysis of findings}

The academic controversy about the specificity of Chinese networks predominantly takes place in economic, sociological, and managerial journals. Most of the publications on networks in China are found in the area of 'Social Capital' (32\%). Studies related to 'Networks of Organizations' or 'Organizational Networks' and 'Embeddedness' account for another $20 \%$ each. About 59\% discuss consequences of networks, applying a functional approach to explain an improvement in performance. As such, most of the literature explains the contribution of network to the overall socio-economic development predominantly in access to resources (48\%) while some other focus on contagion, a more 
deterministic stream explaining a process towards homogeneity in beliefs, norms, values, or outputs (Borgatti et al., 2003).

Methodologically most studies take the 'network' as their unit of analysis. Almost two third of the studies (58\%) are empirical. There is a tendency towards qualitative methods of data collection (68\%). Only in some cases, the scales used in the data collection were being specifically developed to fit the cultural context (38\%). About half of the studies however analyse their data with quantitative methods in most cases simple descriptive statistics. More sophisticated statistical methods are only being used in a small number of studies such as micro-economic studies conducted for instance by the William Davidson Institute (Batjargal, 2005a, 2005b). Within the subset most publications put an explicit focus on China with the intention to test and develop existing Western theories.

Most authors account the significance of networks in China's economic development to cultural factors, predominantly Confucian philosophy (57\%). Yet, they differ with respect to the inherent governance system within networks. While some assume the functioning of 'self-enforcing' governance mechanisms others argue for a form of private arbitration assisted by a 'third-party'. Access to resources and superior forms of coordinating economic behaviour are the functional values of networks most often mentioned in these studies. More than $60 \%$ of authors believe that the impact of networks in the development of China's economy will persists.

\subsection{Network types specific to the Chinese context}

The four generic networks found in the set of literature on China will be presented in this section. First, a brief introduction into the subject of each type of network is given, followed by a presentation of the results. The findings are structured according to the classification scheme described in section 2.2. First, the respective body of literature will be classified into the context of network research. Next, the methodological aspects of the identified literature will be presented. Opinions expressed by the authors with respect to origin, predominant governance mechanisms, attributed functional value, and future of the discussed networks will be described before specific shortcomings of the research on the addressed network will be discussed. 


\section{Qiye jituan - Networks of organizations in business}

Qiye jituans are networks of unrelated, diversified firms (still) under government control established by and around administrative bureaus during the 1980s (Keister, 1998). With the gradual opening of China in 1978, China's political authorities fostered connections between Chinese state-owned enterprises subsequently leading to the creation of these business groups. The motivation for promoting such a development was influenced by the success of the Japanese kereitsu or the Korean chabeol. After fiscal decentralisation transferred control rights and decision-making power to provincial authorities in 1987 they enjoyed considerable popularity when local government agencies considered business groups a promising mean to promote economic development.

In 1995, the official numbers given was 20,000 business groups in the country (Ma \& $\mathrm{Lu}, 2005$ ) when it was also reported that they accounted for approximately one quarter of the total state-owned assets. Their number declined once privatisation policy during the 1990s got off the ground (Keister, 2001). In 1997, the State Council selected 120 qiye jituans to strategically enhance international competitiveness of selected (mostly stateowned) industries while incorporating small and underperforming state companies at the same time (Ma et al., 2005). Today, the share of state-ownership in business groups is estimated between $20 \%$ and $50 \%$; some of them are large enough to be listed in the upper segments of the Fortunes' Global 500 list such as Sinopec, State Grid, or China National Petroleum (Fortune Global 500, 2007).

There are only few studies on qiye jituans before 1998 appearing predominantly in economic and sociological journals. Next to a number of publications on specific alliances within business groups, most studies are positioned in the research on 'Organizational Networks' or 'Networks of Organizations'. There is a clear emphasis on analysing the consequences of these networks mainly in terms of their economic performance. The focus on consequences instead of causes of these networks follows a known pattern of research in all relatively young fields. At an early stage, studies stress the significance of their research object (consequences), while once acknowledged research moves on to more fundamental questions (causes). In general, the type of research conducted in the field of business groups can best be described as an attempt to explain their functional value via an improved access to resources. 
Except for a few publications emphasising dyadic relations within these business networks, most studies focus on the 'network' as unit of analysis. Probably because qiye jituans are assumed to be similar to the Japanese kereitsu or the Korean chabeol, most of them are testing existing Western economic theories. Subsequently, China is taken as a case while the findings are not fed back into the focus of this stream of research. The analysis is dominated by conceptual considerations using static models. There is no clear methodological approach in terms of data collection and analysis, let alone an attempt to adapt scales to the specific cultural context.

Unsurprisingly, most authors agree on the question of the origin of qiye jituans. As constructs of political decision-making their governance is seen as 'authority-driven' despite the structural development towards privatization since their emergence in the 1980s. Access to resources is considered their main functional value. Most studies predict that they will become more important in the future, both in safeguarding the privatization of SOE's, and in creating national champions with the ability to compete internationally. This is reflected in the studies, which emphasize size, economic success, and strategic orientation of a number of these groups, some even going so far as to argue that the deliberate formation of business groups might be beneficial for economies in transition (Keister, 2001).

To sum up, more empirical studies on Chinese business groups are needed. Neither structural approaches to the study of qiye jituans nor studies focusing on their coordinating values were found in the literature. Their contribution to the overall privatization process remains obscure so long as no dynamic models are developed to the effect that the significance of qiye jituans in China's economic development remains unclear. Moreover, since both personal and inter-organizational relationships are recognized as crucial, business groups constitute an intriguing case for multi-level approaches. Finally, concentrating on one firm and examine its interaction with the network might lead to valuable insights; yet, most studies take the 'network' as the unit of analysis. By doing so, the question of network-costs which have to be borne by individual members are avoided and remain an unspecific factor (Nojonen, 2007). 


\section{Overseas Chinese Communities - Networks of organizations in civic society}

Another distinct type of network within the China context is found in organized Chinese communities outside mainland China, so-called Overseas Chinese Communities. Their origin is well researched: In the geographic area of what is now considered China, migration has had a long history. Especially during the $19^{\text {th }}$ and the $20^{\text {th }}$ century many Chinese emigrated to South-East Asia and North America due to political unrest, wars and starvation where often enough they experienced severe discrimination and prosecution (Stuart-Fox, 2003). Nowadays, approximately 60 million Chinese live outside Mainland China, with the highest concentration in South-East Asia (Thailand, Indonesia, Malaysia, and Singapore) and North America. They form a social group with a strong ethnic identity. Assimilation to the new environment does to some extent take place; yet, tradition and language are maintained and cultivated. Overseas Chinese Communities identify themselves not so much by nationality but rather by shared backgrounds such as home village, last name, or clan membership (Jin, 1991). Family ties are valued much more than in other ethnic groups and are maintained both over generations and long distances (Hendrischke, 2007). Many Overseas Chinese Communities support relatives and home villages in China financially. After the opening of China's economy and the acknowledgment of private enterprises, large amounts of foreign investments in China originated from wealthy Overseas Chinese Communities (Wei, Liu, Parker, \& Vaidya, 1999). These are becoming increasingly organized in formal associations and clubs, hosting numerous official conferences and meetings. This process of formalization mainly took place during the last decade as these groups became increasingly exposed to a number of business and political initiatives originating from the People's Republic of China (see for example Anonymous, 2005; Bank of Overseas Chinese, 2007; Overseas Chinese-American Entrepreneurs Association, 2007). Overseas Chinese Communities are not to be considered one unified network. They rather represent a network of separate, yet interrelated networks. Their interlinkages intensify with an increase in the degree of formalization. Simultaneously, their combined influence on the social and economic development in China is directed more strategically and the impact they exert becomes stronger. 
There were only seven publications in the data set dealing with the topic of Overseas Chinese Communities and their impact on China's economic development. Most of them appeared in managerial and sociological journals. ${ }^{2}$ Most of the literature on Overseas Chinese Communities positions itself in the area of 'Organizational Networks' or 'Networks of Organizations'. Studies focus the consequences such as trying o measure their performance or highlighting their impact on international trade or FDI (Gao, 2003; Rauch \& Trindade, 2002).

As has been the case with the studies on business groups, all studies use a connectionist approach to the research question by focusing on the relational embeddedness of actors. Interestingly enough, some studies mention structure as an important factor yet fail to include structure in their line of argumentation. The research reveals a tendency towards explaining contagion, i.e. processes of homogeneity fostering similar attitudes, shared beliefs, and practices (Borgatti et al., 2003).

Methodological approaches too are similar to the studies on business groups. The 'network' itself is the unit of analysis in all publications. Studies are exclusively empirical, in most cases employing quantitative approaches. Because information used is often derived from publicly available statistics on macro-economic indicators, none of the scales applied were adapted to the specific cultural context. This is neither surprising nor questionable since the explanatory power of the studies is restricted to providing a general picture of the influence of Overseas Chinese Communities. Whereas research on business groups, as noted above, is in many perspectives influenced by former research on their Japanese of Korean counterparts, the research on Overseas Chinese Communities mainly contributes to already existing theories. In contrast to Chinese business groups, Overseas Chinese communities can indeed be considered a uniquely Chinese phenomenon, offering attractive data for scrutinizing existing theories. Unsurprisingly, the studies unanimously agree that these networks emerged as historical and political incidents. 'Self-enforcing' governance mechanisms are argued to describe best the internal functioning whose dominant functional value is consequently ascribed to their coordinating advantage. The studies offer an ambiguous scenario for the future of Overseas Chinese Communities and their impact in China's economic development. A

\footnotetext{
${ }^{2}$ It can be assumed that a large body of literature exists in the area of Sinology and anthropology.
} 
majority of studies sees their significance increasing while others both argue for a constant or even diminishing impact.

Similar to the studies on business groups, the one on Overseas Chinese Communities remains under-researched. The review of the literature leaves the impression that the impact of for example Western direct investment is being overestimated, whereas direct investment from Overseas Chinese is regarded as marginal. Studies on Overseas Chinese communities do not use structural approaches. However, the ongoing formalization of these networks makes the use of such approaches an attractive research agenda. Finally, combining economic with sociological and anthropological studies on Overseas Chinese Communities might give insights into their functioning and better enable an assessment of their future role in China’s economy.

\section{Guanxi - Networks of social relations}

The third generic form of networks in China refers to the rather illusive concept of guanxi. Innumerable definitions on guanxi can be found in literature (e.g. Guthrie, 1998; Nee, 1992; Park \& Luo, 2001; Tsang, 1998; Tsui \& Farh, 1997; Yang, 2002). What the majority agrees on is the emphasis on informal social relationships between two or more individuals characterised by notions of trust, familiarity, reliance, and reciprocity (Faure, 2000). Moreover, its strong embeddedness in Chinese culture, its central position in everyday business life, and its strategic importance in inter-organizational relationships are accepted undisputedly (Goodman, 2007). As such, the concept constitutes explicitly or implicitly an integral part of nearly all publications on networks in China. The fast economic development of China not easily explained by the usual macro-economic models has often tempted scholars to search for other explanations; in many cases guanxi seems to be the best alternative. While in the past, guanxi has been considered a major contributing fact for China's economic growth, newer studies emphasise the costs in form of corruption and waste of resources (Nojonen, 2007). Literature on guanxi certainly comprises the earliest studies on networks conducted by Western social science, as already in the $16^{\text {th }}$ and $17^{\text {th }}$ century scholars have noticed the significance of personal relations in the Chinese culture (e.g. Leibniz, 1977). 
The literature on guanxi is large and extremely diverse. Most studies are found in the area of management and sociology. However, as this field of research has a long history, many studies, especially older ones, can be found in history, philosophy, theology, Sinology, and anthropology. With over 55\% of all publications included, guanxi clearly dominates research on networks in China. The focus still lies on explaining the causes of guanxi instead of emphasising its consequences. Only recently have publications emerged that look at both positive and negative aspects of guanxi or show the impact of guanxi in specific business situations, such as HRM practices, alliance formation, or supplier identification (Chen, Chen, \& Xin, 2004; Millington, Eberhardt, \& Wilkinson, 2006). Most research takes place in the area of 'Social Capital', i.e. discussing the value of connections and assessing the impact of a person's ego-network on aspects such as leadership, mobility, employment, or entrepreneurship (Batjargal \& Liu, 2004; Bian, 1997; Davies, Leung, Luk, \& Yiu-Hing Wong, 1995; Li \& Rozelle, 2003). The field is dominated by studies approaching guanxi networks from a connectionist approach, intending to explain deviations in performance where once more 'access to resources' is seen as the crucial advantage.

Guanxi studies focus on individual actors and dyadic relations as unit of analysis. One negative side effect of this is that such a perspective possibly flattens the diverse nature of the impact of guanxi in daily life (Nojonen, 2007). Whereas research on its consequences can be explained by such a simple model, an analysis of its causes requires a more complex unit of analysis, such as interrelated or even multiple networks. In contrast to the studies on business groups and Overseas Chinese Communities, those on guanxi are dominated by qualitative methods, in which in-depth interviews play a central role. Therefore, more studies use scales that were developed for the specific research context. Data analysis is mixed insofar as both qualitative and quantitative methods are being applied. Guanxi studies often serve to develop existing theories. There is a clear tendency towards empirical studies employing static models for assessing the respective research question.

As diverse as the literature on guanxi as diverse are opinions regarding its origin, governance mechanisms, functional value, and future significance. However, one has to be careful with collecting and assessing scholarly opinions on these matters. It is 
noteworthy how many authors seem to adopt opinions and arguments from other scholars without critically examining their justification. This might explain the persistence of the cultural essentialism in these studies which first articulated by Kahn (1979) explained China's surprising economic development by its underlying values found in Confucian writings (Kahn, 1979). Recent publications try to put the record right by showing that significance of social relationships in China has been a side effect of the Cultural Revolution and was intensified by membership in political or military groups such as the People’s Liberation Army (Faure, 2000; Goodman, 2007). Others point out that the art of applying social relations or guanxi in daily business transaction has only emerged recently and has become increasingly difficult and complex since the opening of China's economy (Nojonen, 2002; Wong, 1998). The governance mechanisms most frequently referred to are 'reputation' or 'referral to third-party'. In some studies authors describe this as a self-enforcing mechanism, especially when guanxi is considered rather a network itself instead of merely a dyadic social and informal relationship (Krug, 2006). The functional value of guanxi is mostly ascribed to an improved access to resources, which is in line with the classification of this stream of literature as research on social capital. Finally, the opinions regarding the future role and significance of guanxi are ambiguous. Whereas more than a third of all authors believe guanxi will prevail, only one study explicitly suggests a strengthening role in China's social and business life. Recent studies (after 2000) which argue for a declining role of guanxi, account for approximately one fifth of the publications.

In contrast to the two networks described above, guanxi is extensively being studied by researchers. In fact, it clearly dominates the body of literature on China-specific networks. There is a strong tendency towards explaining the beneficial factors of guanxi, while the 'dark-side' remains underrepresented. One major shortcoming of the literature is the unquestioned Chineseness of guanxi despite the fact that other societies show similar mechanisms and “... have developed similar practices to govern social interaction at some time or another... “ (Goodman, 2007: 176). Yet a debate is needed why and how social relationships seem to be more significant in China than in other business systems. Less quantity and more quality is strongly recommended in this field. Dynamic and longitudinal studies integrating the consequences of guanxi in more concrete and relevant 
organizational settings could yield valuable insights in this respect. This also asks for a shift in terms from 'Social Capital' to 'Embeddedness' studies. A qualified assessment of the future role of guanxi in China for individuals and organizations should then become more plausible.

\section{Network Capitalism - Network as an alternative economic model}

The last identified area of research on generic Chinese networks is of a somewhat different character. The inclusion of this field is rather due to its distinctness in the respective literature than its relatedness to actual modern studies on networks in social science. It concerns an alternative economic model that has been introduced by the notion of network capitalism (Boisot \& Child, 1996) or guanxi capitalism (Hamilton, 1996). What has been proposed is a specific variant of a capitalist system in which the major actor is a network itself. As such, this field of research possibly represents the most promising approach to understanding the significance of networks or social relationships as guanxi in China's socio-economic development. In 1992 already, Biggart and Hamilton have argued that neoclassical economics does poorly when it comes to explaining the process and success of some of Asia's business systems (Biggart \& Hamilton, 1992). Precisely this was the problem that led to a combination of Western economic theories with empirical findings based on other social science approaches as a new way for explaining China's economic development. The focal objective relies on the consequences of a presumably network-driven environment in which not formalized ownership and property rights but relatively uncodified relationships derive legitimacy from social practices (Boisot et al., 1996). Because the research object in this field basically differs from the proceeding three, the initially developed classification scheme was only partially applicable to the selected publications. Moreover, only few articles on this context were found. Nevertheless, the attempt was made to approach this field of network research with a similar method.

Most of the articles are published in economic journals. They mainly argue from a 'Social Capital' perspective, focusing on the consequences of the deep embeddedness of networks. This is insofar not surprising as the topic, Network Capitalism, is based on the assumption of deeply embedded networks in China's social and business environment. Its 
closeness to the social capital area of research indicates that Network Capitalism mainly refers to the importance of personal, informal relations and not to other possible networks such as business groups or Overseas Chinese Communities as described above. Also in line with the findings on social capital and guanxi networks is the explanatory mechanism applied. All publications use a connectionist perspective. They are predominantly conceptual using static models where China serves as a contributing case to (further) develop economic theory.

The term Network Capitalism is found in all possible varieties in studies on networks in China, in many cases leading to conceptual confusions regarding the intentions of the authors. Often, it is merely applied as a buzz term to catch the attention of readers. The absence of a larger body of literature on Network Capitalism indicates both a lack of comparative studies and academic discussion on economic systems. Nevertheless, as argued above, the mere existence of this body of literature can be considered an indicator of the significance of networks in China's and greater Asia's economic development. Research on Network Capitalism seems to be the most promising field of the ones described for enhancing economic and sociological theories. Unfortunately, neither empirical studies nor theoretical contributions in academic journals indicate an existing interest in this field of network research. It is difficult to address possible directions for future research. The emphasis of connectionist approaches to the study of Network Capitalism seem more suitable than structuralist approaches since the value of relationships and not the structural characteristics of networks are to be emphasised. Nevertheless, recent economic and sociological findings on distinct networks in China as the one described above - might yield to new approaches in the study of Network Capitalism.

\section{Conclusion}

\subsection{Summary of findings}

As this overview shows, research on networks in China is diverse in its description and analysis. By systematically analysing the literature on networks in China, four networks have been identified within this field, all of which can be considered generic to the Chinese business environment. While networks in business (qiye jituans), networks in 
the civic society (Overseas Chinese Communities), and Network Capitalism (an alternative economic model), have received limited attention, only guanxi (the network of social relationships) clearly dominates the field. The research on networks in China emphasises access to resource as their dominant functional value, while reduction of transaction costs and risks are less a topic. A comparison with the catalogue of criteria used in the general research on networks shows that the analysis of Chinese networks still lags behind the generally accepted analytical social science frame. Most studies use a connectionist explanatory mechanism and static models to derive arguments and construct models. The emphasis on the consequences of networks might be the reason why a cultural, only limitedly substantiated explanation for the relative significance of networks in China still prevails in the academic discussion. Only recently have researchers begun to move away from this cultural essentialism towards more substantiated explanations (Hendrischke, 2007; Wank, 1996). A significant number of studies insists on China being a research topic sui generis, following the callings of a number of scholars to discard existing (neoclassical) economic theories because of their limited ability to explain processes taking place in a number of (especially Asian transitory) economies.

\subsection{Implications for future research}

Despite the large variety of research on networks in China, the results of this study suggest some future directions for the field. More research on business groups, Overseas Chinese Communities, and Network Capitalism is needed while the field could most likely spare more studies on guanxi.

The subject of business groups might benefit from more empirical studies using a structuralist approach. On the one hand, they seem suitable for multiple-network analysis since both personal and professional ties between group members are assumed to be significant. On the other hand, case studies on individual organizations within business groups might yield insights into the positive and negative implications of membership. Similar to business groups, research on Overseas Chinese Communities will benefit from structuralist approaches which should be easier to conduct in the future due to the process of formalization taking place within and between these communities. The stream of 
specific network literature addressing guanxi needs to move to dynamic models focusing on the implications of embedded informal, personal relationships. One of the major fallacies in this field is the large number of studies doing not much more than emphasising the presence of networks and social relations in China. However, as Boisot and Child (1996) phrased it, “... it is not the presence of networking that is distinctive about China's emerging economic order but, rather, the depth and nature of its social embeddedness." (Boisot et al., 1996: 623). Many studies on guanxi continue to explain functioning and consequences, while failing to carve out the distinctiveness, i.e. the relative significance, of personal and informal relationships in China compared to other economic environments. Much needed research on the costs of guanxi is also still largely missing (exception Nojonen, 2007). Lastly, the field of Network Capitalism will benefit both from better endogenizing the three types of networks and from an intensified discussion on comparative business systems.

One type of research on networks, despite its promising contributions, has been entirely disregarded by studies on networks in China. Studies on Convergence focus on processes of social and environmental shaping (Borgatti et al., 2003). The basic concept underlying this field is structural equivalence proposing actors in an environment to be structurally similar in being linked to the same partners. Taking an attributal perspective these studies intend to explain homogeneity between actors. Both structural and relational elements are being combined. If networks indeed significantly characterise and affect the Chinese economic development, then the effects of structural equivalency should be well observable in this environment. Borgatti et al. suggest that especially institutional theories fit in this area (Borgatti et al., 2003). Dynamic models will lead to deeper insights into the actual functioning and relative significance of networks. These approaches should moreover yield to further understanding the relation between formal and informal institutions in China's socio-economic development.

\section{Discussion}

Networks are neither linked to a specific culture nor, as economic historians have shown, to a specific period of time (Faure, 2000; Greif, 2006; Tilly, 1987). The fact that networks seem to be everywhere and nowhere is the outcome of how economic and social collective action is perceived in social sciences. While anthropology and parts of 
the China-specific literature regard networks as exogenously given, social groups based on shared values, or family relations which defy further analysis, the problem within economics is that networks were originally situated between markets and hierarchies. Yet, the case of China gives further evidence to the claim that networks are not a distinct coordination mechanism that can simply be added to other forms of coordination, let alone economic regimes. Instead, networks can be combined with all other coordinating forms and cultures. They might differ in origin, purpose, professionalism, and embeddedness. Despite this, what they have in common is the use of social relations as a base for pursuing socio-economic goals by collective action.

China in this respect offers a unique environment for the study of networks. Their relative significance in the country's economy long has been emphasised. The absence of rigid institutional arrangements as known in the West moreover seemingly speeds up the process of change in China resulting in dynamics facilitating the study of networks. However, the conduction of research in China implies a number of difficulties challenging researchers' possibilities in designing social studies as transparently as in other economies. While evaluating findings of this study as well as results of future research these challenges have to be kept in mind. Despite these specific characteristics, China and its economic development offer chances to substantially enhance existing theories in modern Western social sciences. 


\section{Literature}

Abhik, R., Walters, P. G. P., \& Luk, S. T. K. 2001. Chinese puzzles and paradoxes Conducting business research in China. Journal of Business Research, 52(2): 203-210.

Academy of Management Journal. 1997. Special Research Forum on Alliances and Networks. Academy of Management Journal, April(2): 253-484.

Acta Sociologica. 1994. Special Issue on Social Network Analysis. Acta Sociologica 37: 327328.

Anonymous. 1991. Family Instructions, The Chinese - Adapting the Past, Facing the Future, Vol. 2.: 317-326. Ann Arbor, Michigan: The University of Michigan.

Anonymous. 2005. Roundup: Overseas Chinese communities back Anti-Secession Law, People's Daily Online, Vol. 2007. Beijing: People's Daily Online.

Bank of Overseas Chinese. 2007. History of Bank of Overseas Chinese, Vol. 2007: Bank of Overseas Chinese.

*Batjargal, B. 2005a. Network Triads: Transitivity, Referral and Venture Capital Decisions in China and Russia. Working Papers (William Davidson Institute) -- University of Michigan Business School: 1-33.

*Batjargal, B. 2005b. Software entrepreneurship: Knowledge Networks and Performance of software ventures in China and Russia. Cambridge: The William Davidson Institute.

Batjargal, B., \& Liu, M. 2004. Entrepreneurs' Access to Private Equity in China: The Role of Social Capital. Organization Science, 15(2): 159-172.

*Bian, Y. 1997. Bringing strong ties back in: Indirect ties, network bridges, and job searches in China. American Sociological Review, 62(3): 366-385.

*Bian, Y., Breiger, R., Davis, D., \& Galaskiewicz, J. 2005. Occupation, Class, and Social Networks in Urban China. Social Forces, 83(4): 1443-1468.

Biggart, N. W., \& Hamilton, G. G. 1992. On the limits of a firm-based theory to explain business networks: The Western bias of neoclassical economics. In R. G. Eccles, \& N. Nitin (Eds.), Networks and Organizations: Structure, Form, and Action: 471-490. Boston: Harvard Business School Press.

*Björkman, I., \& Kock, S. 1995. Social Relationships and Business Networks: the Case of Western Companies in China. International Business Review, 4(4): 519.

Boisot, M., \& Child, J. 1988. The Iron Law of Fiefs: Bureaucratic Failure and the Problem of Governance in the Chinese Economic Reforms. Administrative Science Quarterly, 33(4): 507.

*Boisot, M., \& Child, J. 1996. From Fiefs to Clans and Network Capitalism: Explaining China's Emerging Economic Order. Administrative Science Quarterly, 41(4): 600-628.

*Boisot, M., \& Child, J. 1999. Organizations as Adaptive Systems in Complex Environments: The Case of China. Organization Science, 10(3): 237-252.

Borgatti, S. P., \& Foster, P. C. 2003. The network paradigm in organizational research: A review and typology. Journal of Management, 29(6): 991-1031.

Burt, R. S. 1997. The Contingent Value of Social Capital. Administrative Science Quarterly, 42(2): 339-365.

*Carney, M. 1998. The competitiveness of networked production: The role of trust and asset specificity. Journal of Management Studies, 35(4): 457.

*Che, A. 2000. A New Relationship Network. China Business Review, 27(6): 42.

*Chen, C.-J. J. 2005. The Path of Chinese Privatisation: a case study of village enterprises in southern Jiagnsu. Corporate Governance: An International Review, 13(1): 72-80.

*Chen, C. C., Chen, Y.-R., \& Xin, K. 2004. Guanxi Practices and Trust in Management: A Procedural Justice Perspective. Organization Science, 15(2): 200-209. 
*Chen, H. H. C., \& Chen, T.-J. T. C. 1998. Network Linkages and Location Choice in Foreign Direct Investment. Journal of International Business Studies, 29(3): 445-467.

Coleman, J. 1990. Foundations of Social Theory. Camebridge, MA: Belknap Press.

*Davies, H., Leung, T. K. P., Luk, S. T. K., \& Yiu-Hing Wong, S. T. K. 1995. The Benefits of "Guanxi" The Value of Relationships in Developing the Chinese Market. Industrial Marketing Management, 24(3): 207-214.

DiMaggio, P. 1997. Culture and Cognition. Annual Review of Sociology, 23(1): 263.

Farh, J.-L., Cannella, A. A., Lee, C., \& Lee, J. 2006. Approaches to Scale Development in Chinese Management Research. Management and Organizational Review, 2(3): 301318.

*Farh, J.-L., Tsui, A. S., Xin, K., \& Cheng, B.-S. 1998. The Influence of Relational Demography and Guanxi: The Chinese Case. Organization Science, 9(4): 471.

Faure, D. 2000. The Mackay Treaty of 1902 and Its Impact on Chinese Business. Asia Pacific Business Review, 7(2): 81.

Fortune Global 500. 2007. Fortune Global 500: List of Chinese Companies, Vol. 2007: CNN Money.com

*Gabrowski, R. 2002. Constructing National Economic Interests. Journal of the Asia Pacific Economy, 7(3): 310-334.

*Gao, T. 2003. Ethnic Chinese networks and international investment: evidence from inward FDI in China. Journal of Asian Economics, 14(4): 611-629.

*Gómez Arias, J. T. 1998. A relationship marketing approach to guanxi. European Journal of Marketing, 32(1/2): 145-156.

Goodman, D. S. G. 2007. Narratives of Change: Culture and Local Economic Development In B. Krug, \& H. Hendrischke (Eds.), The Chinese Economy in the 21st Century: 175-201. Cheltham, UK; Northampton, MA, USA: Edward Elgar.

Granovetter, M. 1985. Economic Action and Social Structure: The Problem of Embeddedness. The American Journal of Sociology, 91(3): 481-510.

Greif, A. 2006. Institutions and the path to the modern economy. Cambridge: Cambridge University Press.

*Guthrie, D. 1998. The Declining Significance of Guanxi in China's Economic Transition. The China Quarterly(154): 254-282.

*Haley, G. T. 1997. A strategic perspective on overseas Chinese networks' decision-making. Management Decision, 35(7/8): 587.

*Haley, U. C. V., \& Haley, G. T. 2006. The logic of Chinese business strategy: East versus West: Part I. Journal of Business Strategy, 27(2): 35-42.

Hamilton, G. G. 1996. Business Networks and Economic Development in East and Southeast Asia. In G. G. Hamilton (Ed.), Asian Business Networks, 64 ed.: 302. Berlin, New York: Walter de Gruyer.

*Hendrischke, H. 2004. The Role of Social Capital, Networks and Property Rights in China's Privatization Process. In B. Krug (Ed.), China's Rational Entrepreneurs: 97-118. London, New York: RoutledgeCurzon.

Hendrischke, H. 2007. Networks as Business Networks. In B. Krug, \& H. Hendrischke (Eds.), The Chinese Economy in the 21st Century: 202-222. Cheltham, UK; Northampton, MA, USA: Edward Elgar.

Holmström, B., \& Roberts, J. 1998. The Boundaries of the Firm Revisited. Journal of Economic Perspectives, 12(4): 73-94.

*Hutchings, K., \& Murray, G. 2002. Working with Guanxi: An Assessment of the Implications of Globalisation on Business Networking in China. Creativity \& Innovation Management, 11(3): 184-191. 
Jin, B. 1991. The Family. In R. F. Dernberger, K. J. DeWoskin, S. M. Goldstein, R. Murphey, \& M. K. Whyte (Eds.), The Chinese - Adapting the Past, Facing the Future, Vol. 2.: 326339. Ann Arbor, Michigan: The University of Michigan.

Kahn, H. 1979. World economic development : 1979 and beyond. London: Croom Helm.

*Keister, L. A. 1998. Engineering Growth: Business Group Structure and Firm Performance in China's Transition Economy. American Journal of Sociology, 104(2): 404-440.

*Keister, L. A. 2001. Exchange Structures in Transition: Lending and Trade Relations in Chinese Business Groups. American Sociological Review, 66(3): 336-360.

*Khanna, T. 2000. Business groups and social welfare in emerging markets: Existing evidence and unanswered questions. European Economic Review, 44(4-6): 748-761.

*Khatri, N., Tsang, E. W. K., \& Begley, T. M. 2006. Cronyism: a cross-cultural analysis. Journal of International Business Studies, 37(1): 61-75.

*Kiong, T. C., \& Kee, Y. P. 1998. Guanxi Bases, Xinyong and Chinese Business Networks. The British Journal of Sociology, 49(1): 75-96.

Klein, K. J., Lim, B.-C., Saltz, J. I., \& Mayer, D. M. 2004. How do they get there? An examination of the antecedents of centrality in team networks. Academy of Management Journal, 47(6): 952-963.

*Krug, B. 2003. Networks in cultural, economic, and evolutionary perspective. Paper presented at the "Towards a Chinese Enterprise Model - Chinese enterprises and their institutional environment, Sydney.

Krug, B. 2004. Introduction: New opportunities, new sector, new firms. In B. Krug (Ed.), China's rational entrepreneurs, Vol. 20: 1-20. London and New York: RoutledgeCruzon.

Krug, B. 2006. China: Fakten oder Fiktion? In D. Ruloff (Ed.), China und Indian: Supermächte des 21. Jahrhunderts?, Vol. 34: 61-74. Chur/Zürich: Rüegger Verlag.

Krug, B. 2007. Enterprise Ground Zero in China. In B. Krug, \& H. Hendrischke (Eds.), The Chinese Economy in the 21st Century: 113-144. Cheltham, UK; Northampton, MA, USA: Edward Elgar.

*Krug, B., \& Belschak, F. 2001. Combining Commerce and culture: Establishing business relations in China. In ERIM (Ed.), ERIM Report Series Research in Management. Rotterdam: Erasmus University Rotterdam.

*Krug, B., \& Hendrischke, H. 2003. China Incorporated: Property Rights, Networks, and the Emergence of a Private Business Sector in China. Managerial Finance, 29(12): 32-44.

Krug, B., \& Hendrischke, H. 2007. Framing China: Transformation and Institutional Change through Coevolution. Management and Organization Review, (forthcoming).

Leibniz, G. W. 1977. Discourse on the Natural Theology of the Chinese (1646-1716) Honolulu: University Press of Hawaii.

*Li, H., \& Rozelle, S. 2003. Privatizing Rural China: Insider Privatization, Innovative Contract and the Performance of Township Enterprises. The China Quarterly, 176: 981-1005.

*Liu, H. 1998. Old Linkages, New Networks: The Globalization of Overseas Chinese Voluntary Associations and Its Implications. China Quarterly(155): 582-609.

*Luo, Y. 1997. Guanxi: Principles, philosophies, and implications. Human Systems Management, 16(1): 43.

*Ma, X., \& Lu, J. W. 2005. The critical role of business groups in China. Ivey Business Journal, May/June: 1-12.

*Michailova, S., \& Worm, V. 2003. Personal Networking in Russia and China:: Blat and Guanxi. European Management Journal, 21(4): 509.

*Millington, A., Eberhardt, M., \& Wilkinson, B. 2005. Gift Giving, Guanxi and Illicit Payments in Buyer -- Supplier Relations in China: Analysing the Experience of UK Companies. Journal of Business Ethics, 57(3): 255-268.

*Millington, A., Eberhardt, M., \& Wilkinson, B. 2006. Guanxi and supplier search mechanisms in China. Human Relations, 59(4): 505-531. 
*Nee, V. 1992. Organizational Dynamics of Market Transition: Hybrid Forms, Property rights, and Mixed Economy in China. Administrative Science Quarterly, 37(1): 1-27.

Nojonen, M. 2002. The Competitive Advantage with Chinese Characteristics: the Sophisticated Choreography of Gift-Giving. In J. Kidd, \& F.-J. Richter (Eds.), Corruption and Governance in Asia. New York: Palgrave Macmillan.

Nojonen, M. 2007. Guanxi - The Chinese Third Arm. Unpublished Dissertation, Universitas Oeconomica Helsingiensis, Helsinki.

OED. 2006. Oxford English Dictionary Online. Oxford: Oxford University Press.

Organization Studies. 2003. Special Issue on 'Institutions, Markets, and Organizations'. Organization Studies, 24(11): 1579-1580.

Overseas Chinese-American Entrepreneurs Association. 2007. History of Overseas ChineseAmerican Entrepreneurs Association, Vol. 2007: Overseas Chinese-American Entrepreneurs Association.

*Park, S. H., \& Luo, Y. 2001. Guanxi and Organizational Dynamics: Organizational networking in Chinese firms. Strategic Management Journal, 22(5): 455.

*Parnell, M. F. 2005. Chinese business guanxi: an organization or non-organization? Journal of Organisational Transformation \& Social Change, 2(1): 29-47.

*Peng, M. W. 1997. Firm Growth in Transitional Economies: Three Longitudinal Cases From China, 1989-96. Organization Studies (Walter de Gruyter GmbH \& Co. KG.), 18(3): 385.

Peng, M. W. 2003. Institutional transitions and strategic choice. Academy of Management Review, 28(2): 275-286.

*Peng, M. W., \& Zhou, J. Q. 2005. How Network Strategies and Institutional Transitions evolve in Asia. Asia Pacific Journal of Management, 22(4): 321-336.

*Peng, Y. 2004. Kinship Networks and Entrepreneurs in China's Transitional Economy. American Journal of Sociology, 109(5): 1045-1074.

*Pistrui, D., Huang, W., Oksoy, D., Jing, Z., \& Welsch, H. 2001. Entrepreneurship in China: Characteristics, Attributes, and Family Forces Shaping the Emerging Private Sector. Family Business Review, 14(2): 141-152.

*Rauch, J. E., \& Trindade, V. 2002. Ethnic Chinese networks in international trade. Review of Economics \& Statistics, 84(1): 116.

*Redding, G. 1995. Overseas Chinese Networks: Understanding the Enigma. Long Range Planning, 28(1): 61-69.

*Saxenian, A. 2002. Transnational Communities and the Evolution of Global Production Networks: The Cases of Taiwan, China and India. Industry \& Innovation, 9(3): 183-202.

*Standifird, S. S., \& Marshall, R. S. 2000. The Transaction Cost Advantage of Guanxi-Based Business Practices. Journal of World Business, 35(1): 21.

Strategic Management Journal. 2000. Special issue: Strategic Networks. Strategic Management Journal, 10(4): 199-425.

Stuart-Fox, M. 2003. A Short History of China and South East Asia: Tribute, Trade and Influence. Crows Nest, Australia: Allen \& Unwin.

*Tang, F., \& Xi, Y. 2006. Exploring dynamic multi-level linkages in inter-organizational networks. Asia Pacific Journal of Management, 23(2): 187-208.

Tilly, C. 1987. The analysis of popular collective action. European Journal of Operational Research, 30(3): 223-229.

*Tsang, E. W. K. 1998. Can guanxi be a source of sustained competitive advantage for doing business in China? Academy of Management Executive, 12(2): 64-73.

Tsui, A. S., \& Farh, J.-L. L. 1997. Where Guanxi Matters. Work \& Occupations, 24(1): 56-79.

*Tung, R. L., \& Worm, V. 2001. Network capitalism: the role of human resources in penetrating the China market. International Journal of Human Resource Management, 12(4): 517534. 
Uzzi, B. 1997. Social Structure and Competition in Interfirm Networks: The Paradox of Embeddedness. Administrative Science Quarterly, 42: 35-67.

van der Sprenkel, S. 1991. Urban Social Control. In R. F. Dernberger, K. J. DeWoskin, S. M. Goldstein, R. Murphey, \& M. K. Whyt (Eds.), The Chinese - Adapting the Past, Facing the Future, Vol. 2.: 363-367. Ann Arbor, Michigan: The University of Michigan.

*Vanhonacker, W. R. 2004. Guanxi Networks in China. China Business Review, 31(3): 48-53.

*Wank, D. L. 1995. Private Business, Bureaucracy, and Political Alliance in a Chinese City. The Australian Journal of Chinese Affairs, 33: 55-71.

*Wank, D. L. 1996. The Institutional Process of Market Clientelism: Guanxi and Private Business in a South China City. China Quarterly(147): 820-838.

Wei, Y., Liu, X., Parker, D., \& Vaidya, K. 1999. The Regional Distribution of Foreign Direct Investment in China. Regional Studies, 33(9): 857-867.

Whyte, M. K. 1991. The Commune as a Social System. In R. F. Dernberger, K. J. DeWoskin, S. M. Goldstein, R. Murphey, \& M. K. Whyt (Eds.), The Chinese - Adapting the Past, Facing the Future, Vol. 2.: 368-375. Ann Arbor, Michigan: The University of Michigan.

Williamson, O. E. 1975. Markets and hierarchies: analysis and antitrust implications: a study in the economics of internal organization. New York, NY: Free Press.

*Wong, P. L.-K., \& Ellis, P. 2002. Social Ties and Partner Identification in Sino-Hong Kong International Joint Ventures. Journal of International Business Studies, 33(2): 265-289.

*Wong, S.-1. 1985. The Chinese Family Firm: A Model. The British Journal of Sociology, 36(1): 58-72.

*Wong, Y. H. 1998. The Dynamics of Guanxi in China. Singapore Management Review, 20(2): 25-42.

*Xin, K. K., \& Pearce, J. L. 1996. Guanxi: Connections as substitutes for formal institutional support. Academy of Management Journal, 39(6): 1641.

*Yang, M. M.-H. 1989. The Gift Economy and State Power in China. Comparative Studies in Society and History, 31(1): 25-54.

*Yang, M. M.-H. 2002. The Resilience of guanxi and its New Developments: A critique of some new guanxi scholarship. The China Quarterly: 459-476.

*Yeung, I. Y. M., \& Tung, R. L. 1996. Achieving Business Success in Confucian Societies: The Importance of Guanxi (Connections). Organizational Dynamics, 25(2): 54-65.

Zhao, X. B., \& Tong, S. P. 2000. Unequal economic development in China: Spatial distribution and regional policy reconsiderations, 1985-1995. Regional Studies, 34(6): 549-561.

Zheng, Y. 1991. Connections. In R. F. Dernberger, K. J. DeWoskin, S. M. Goldstein, R. Murphey, \& M. K. Whyte (Eds.), The Chinese - Adapting the Past, Facing the Future, Vol. 2.: 317-326. Ann Arbor, Michigan: The University of Michigan.

*Zheng, Z., Anand, J., \& Mitchell, W. 2005. A Dual Networks Perspective on InterOrganizational Transfer of R\&D Capabilities: International Joint Ventures in the Chinese Automotive Industry. Journal of Management Studies, 42(1): 127-160. 